\title{
Article \\ Superhydrophobic Candle Soot Coating Directly Deposited on Aluminum Substrate with Enhanced Robustness
}

\author{
Hussein Ali Hussein ${ }^{1}$ (D), Sabah Ibrahim Wais ${ }^{1}$ (D) and Khedir R. Khedir ${ }^{1,2, *(\mathbb{D})}$ \\ 1 Physics Department, College of Sciences, University of Duhok, Duhok 42001, Kurdistan Region, Iraq; \\ hussein.ali@uod.ac (H.A.H.); sabahwais@uod.ac (S.I.W.) \\ 2 College of Arts and Science, The American University of Kurdistan, Duhok 42001, Kurdistan Region, Iraq \\ * Correspondence: khedir.ramazan@auk.edu.krd; Tel.: +964-7510086018
}

check for updates

Citation: Hussein, H.A.; Wais, S.I.; Khedir, K.R. Superhydrophobic Candle Soot Coating Directly Deposited on Aluminum Substrate with Enhanced Robustness. Coatings 2022, 12, 202. https://doi.org/ 10.3390/coatings12020202

Academic Editor: Jinyang $\mathrm{Xu}$

Received: 23 December 2021

Accepted: 29 January 2022

Published: 4 February 2022

Publisher's Note: MDPI stays neutral with regard to jurisdictional claims in published maps and institutional affiliations.

Copyright: (c) 2022 by the authors. Licensee MDPI, Basel, Switzerland. This article is an open access article distributed under the terms and conditions of the Creative Commons Attribution (CC BY) license (https:/ / creativecommons.org/licenses/by/ $4.0 /)$.

\begin{abstract}
In this study, superhydrophobic surfaces were developed by using a simple and environmentally friendly technique. The nano-network of candle soot (CS) as the byproduct of incomplete combustion of paraffin candle was directly coated onto both smooth and micro-rough aluminum (Al) substrates for various time periods of deposition. The simple technique of mechanical sanding was used to impart micro-rough structures onto Al substrates using different sandpaper grit sizes. The scanning electron microscopy (SEM), energy dispersive X-ray spectroscopy (EDS), atomic force microscopy (AFM), and X-ray diffraction (XRD) techniques were used to characterize the morphology and chemistry of the prepared surfaces. Wetting analysis of the prepared surfaces was performed by measuring both water droplet contact angle (CA) and sliding angle (SA). The prepared coatings showed superhydrophobic properties with high CAs and low SAs for CS surfaces coated on roughened Al substrates. Moreover, the robustness of the prepared surfaces was tested by continuous impingement of water droplets onto their surfaces from various heights. Post-testing wetting analysis showed that the micro-nano surfaces of candle soot coated on micro roughened Al substrates demonstrated improved robustness. These surfaces could be useful for self-cleaning, anti-corrosion and anti-icing applications.
\end{abstract}

Keywords: nano network candle soot; aluminum; mechanical sanding; superhydrophobicity; robustness

\section{Introduction}

For the last two decades, there has been a significant amount of research devoted to the fabrication of surfaces with super water-repellent properties known as superhydrophobic surfaces due to their wide range of industrial applications [1-4]. The concept was inspired by the way that natural materials' outer layers have evolved to efficiently interact with their surrounding environments. The lotus leaf is an example of a plant that has a unique way to survive in its wetting and moisture environment, which is exemplified by its super repellant property in terms of water. The plant's surface is covered with a combination of micro-scale bumps and nano-scale hair-like waxy material [5].

Superhydrophobic surfaces have a water contact angle of more than $150^{\circ}$ and a sliding angle of less than $10^{\circ}$ [6-9]. The key to this property is the surface roughness and low surface energy of the surface. In terms of roughness, micro or nano or a combination of both micro-nano structures are imparted onto substrates. For high surface energy materials such as metals, the surface chemistry of the obtained rough structures is reduced with low-energy hydrocarbons or fluorocarbon compounds $[6,8,10,11]$. For low surface energy materials such as polymers, roughness alone is sufficient for obtaining the superhydrophobic property.

Depending on the nature of the substrate's material, various techniques have been used to impart rough structures onto surfaces such as dip coating [12], laser ablation [13-15], glancing-angle deposition (GLAD) [16], chemical vapor deposition (CVD) [17], Electrospinning [18], sol-gel processing [19], spray coating [20,21], self-assembly and transferred [22], 
and hot water treatment $[23,24]$. For metallic substrates such as Al, Rico et al. [25] used the laser ablation method and then grafted the imparted rough structures with fluorocarbon molecular chains to obtain superhydrophobic surfaces. Barthwal et al. [26] used chemical etching to roughen the Al substrate and then coated the produced rough structures with polydimethylsiloxane thermal vapor deposition. In another work, Milles et al. [27] prepared superhydrophobic Al surfaces using direct laser interference patterning without lowering rough structures' surface energy. Most of the coated materials and techniques suffer from high costs and/or have chemical byproducts.

Carbon-based materials have been widely used in research for many potential applications due to their biocompatibility, low cost, and also their versatile nanoscale allotropes with various shapes and sizes such as fullerenes, graphene, nanotubes, nanowires, and carbon soot. The development of superhydrophobic surfaces using this "magic" material has also drawn significant attention as its also hydrophobic $[20,22,28]$. Recently, carbon soot as a network of nanoparticles and as a byproduct of combustion has also received attention for developing superhydrophobic surfaces. [8,9,29]. Qahtan et al. [20] used the spraying technique to deposit candle soot on a glass substrate to produce superhydrophobic surfaces. The results showed water jet resistance and thermally stable properties. Wu et al. [30] also used candle soot mixed with silica shells and polydimethylsiloxane to prepare superhydrophobic surfaces with icephobic properties.

Despite the large number of techniques and materials used to develop superhydrophobic surfaces, the cost, durability of coatings, and the environmental impact of the fabrication process have always been the main challenge to overcome. Here in this work, we used a simple technique of direct coating of the candle soot on a roughened Al metallic substrate to develop superhydrophobic surfaces. The simple technique of mechanical sanding is used to introduce micro-rough structures to Al substrates to enhance the robustness of the prepared coatings. Deposition time periods of the candle soot and various sandpaper grit sizes were utilized to optimize the functionality of prepared coatings. These two simple techniques, besides having low costs, are also environmentally friendly techniques.

\section{Materials and Methods}

\subsection{Sample Preparation}

The Al alloy 2024 that is commercially available was cut into substrates with dimensions of $2 \mathrm{~cm} \times 2 \mathrm{~cm}$. Locally available paraffin candles were purchased for candle soot deposition on the prepared $\mathrm{Al}$ substrates. For preparing smooth candle soot coated $\mathrm{Al}$ surfaces, first, Al substrates were polished with fine 3000 and 4000 grit size sandpapers and then ultrasonicated with acetone for the removal of the inherent oxide layer. Next, the smoothened clean surfaces were held directly above the candle at a distance of $2 \mathrm{~cm}$ for carbon soot deposition for different time periods of 3, 5, 10, 20, and 40 s. For preparing combined micro-nano structures, another set of Al substrates were sanded using different coarse sandpapers with grit sizes of 60,100,220, and 400. Then the prepared clean micro-rough Al surfaces were each held directly above the candle flame for carbon soot deposition for the time periods of $3,5,10,20$, and $40 \mathrm{~s}$. The preparation procedure of the two sets of CS coated on both smooth and rough Al substrates are shown in Figure 1. 


\section{a. Nano Candle Soot Coating on smooth Al substrate}

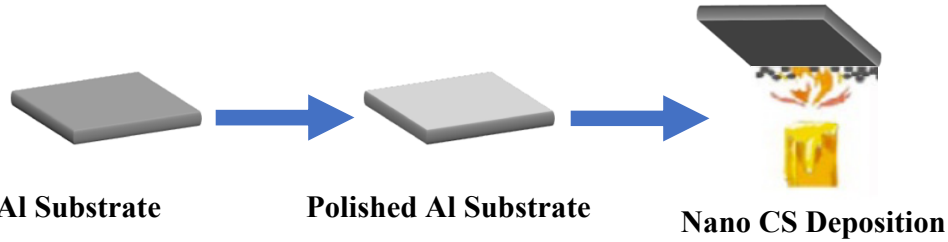

\section{b. Nano Candle Soot Coating on micro-rough Al substrate}

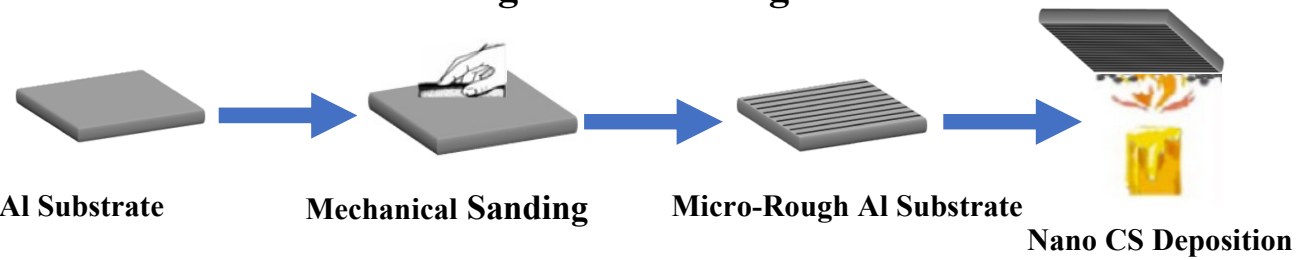

Figure 1. Schematic representation of direct coating of Candle Soot on both (a) smooth Al substrate and $(\mathbf{b})$ micro roughened $\mathrm{Al}$ substrate.

\subsection{Characterization}

Field emission scanning electron microscopy (FESEM, Zeiss-Gimini 560, Zeiss, Jena, Germany) was used to image the top-view and side-view of the CS coated on both smooth and rough Al substrates. An energy dispersive X-ray (EDS) spectrometer (Zeiss, Jena, Germany) attached to the FESEM unit was used to characterize the elemental composition of the surfaces. Atomic Force Microscopy (AFM, nanosurf, Liestal, Switzerland) was used to characterize the topography of some randomly selected samples to verify the images taken by FESEM. Furthermore, the wetting properties (static and dynamic) of both sets of prepared CS coatings were characterized by a homemade contact angle (CA) measurement unit, as shown in Figure S1, using the sessile drop method and ImageJ software (1.53a). The de-ionized water droplets of $2 \mu \mathrm{L}$ size were gently dispensed on the prepared surfaces to measure their water contact angles (CAs) and by tilting the surfaces the sliding angles (SAs) were also recorded. For accuracy, the measurements collected from more than 5 pristine samples were averaged and then reported.

\subsection{Robustness Test}

The robustness of the prepared CS coatings possessing optimal water repellency was examined using water droplet impingement from two different heights of 5 and $10 \mathrm{~cm}$. The process was carried out by dripping $2 \mathrm{~mL}$ of water droplets on the same location of the selected CS coating surfaces from a $5 \mathrm{~cm}$ height. Afterward, water droplet CAs and SAs were again measured from the locations were under droplets impingement. The same process was repeated for the height of $10 \mathrm{~cm}$ with another set of pristine samples. The reported data were averaged from three pristine samples before and after treatment.

\section{Results and Discussion}

The top-view SEM images of the CS directly deposited on smooth aluminum substrates for various time periods of 3, 5, 10, 20, and $40 \mathrm{~s}$ are shown in Figure 2a-e. The porosity of the coating slightly decreased with the increase in the deposition time as the network became more compact with a slight increase in the size of nanoparticles which can be noticed in the corresponding inset SEM images. On average, the size of agglomerated nanoparticles is between 40 to $70 \mathrm{~nm}$ across 3 and $40 \mathrm{~s}$ deposition time periods, respectively. Furthermore, the thickness of the coating significantly increased with the increase in the time of deposition as shown in the side-view SEM images presented in Figure $2 \mathrm{f}-\mathrm{j}$. To the best of our knowledge, this is the first time in which the side-view SEM images have been reported for CS coatings in terms of time deposition. The deposited network of nanoparticles has different thicknesses (D1) of around $8,12,18,37$, and $67 \mu \mathrm{m}$ for different 
deposition time periods of 3,5,10,20, and 40 s, respectively. The thickness values indicate a linear increase of around $2-3 \mu \mathrm{m}$ in the growth of porous CS nano-network for each extra second of deposition time. A figure showing the values of thicknesses of deposited CS per each deposition time is provided in the supporting material (Figure S3).
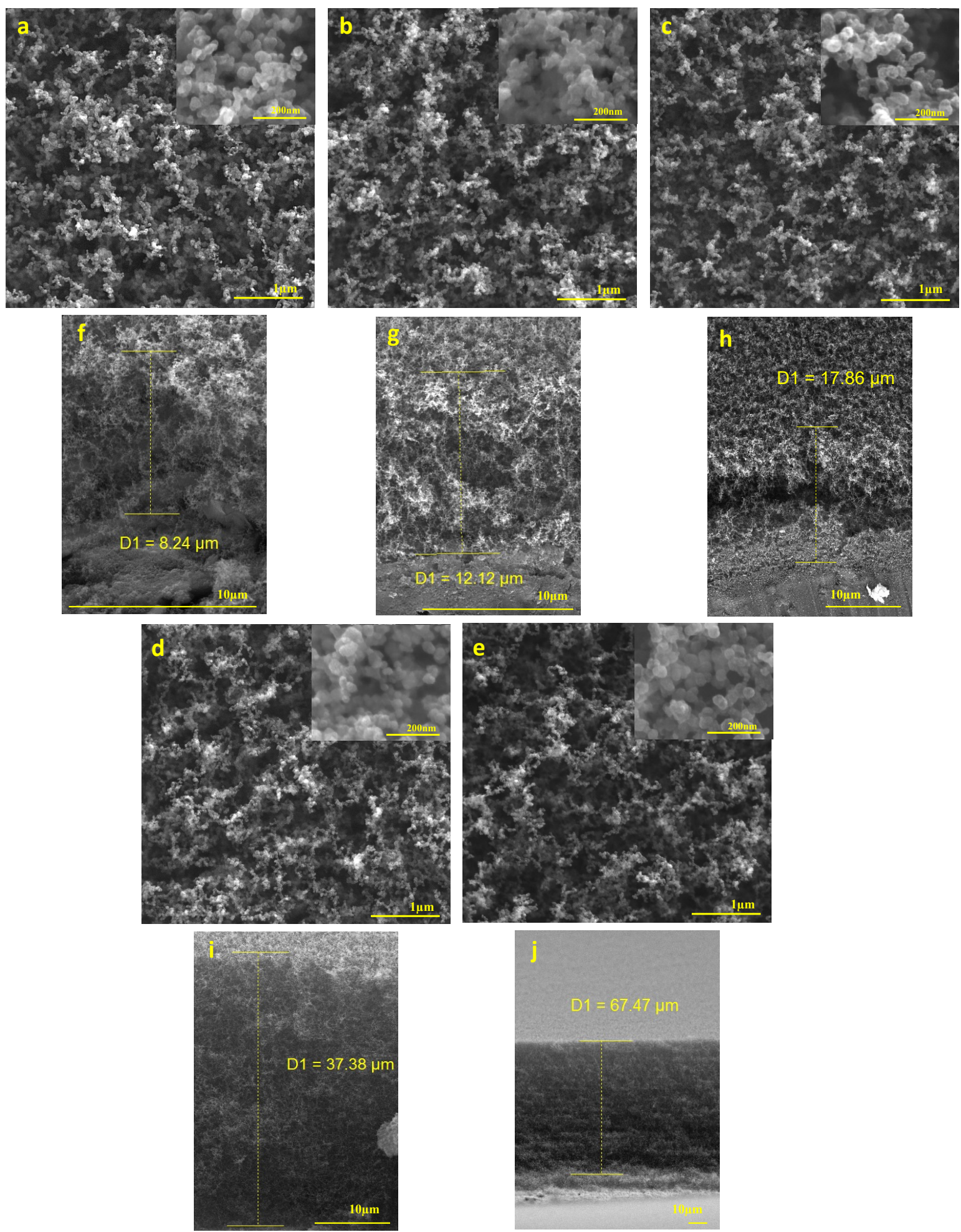

Figure 2. Top-view (a-e) and corresponding side-view (f-j) SEM images of CS nano-network directly coated on smooth Al substrate for different time periods of (a) $3 \mathrm{~s}$, (b) $5 \mathrm{~s}$, (c) $10 \mathrm{~s}$, (d) $20 \mathrm{~s}$, and (e) $40 \mathrm{~s}$. (D1 represents the thickness of the coating). 
This nanonetwork of CS material reported in this study has been previously reported. Zhang et al. [9] deposited CS on the Al substrate for a time period of $30 \mathrm{~s}$. The reported structures show a fractal-like network of nanoparticles which was attributed to the incomplete combustion process of the paraffin candle. In another study, Zhang et al. [9] reported that the structure of the prepared coatings with the nanoparticle of CS coated on Al alloy substrate has revealed a porous network. Using different substrates including metallic, glass, ceramic, and adhesive paper, Wei et al. [31] also reported a similar nanonetwork structure of CS material when coated for a period of 10-20 s. In terms of the CS coating's thickness, Wu et al. [30] manipulated the thickness of the deposited CS material by altering the deposition time. Esmeryan et al. [7] reported nanonetwork CS particles with sizes around $\sim 50 \mathrm{~nm}$ when it was coated on the glass substrate using the epoxy resin and glow discharge RF plasma.

In order to verify the images taken by SEM, the topography of some randomly selected samples was captured using AFM microscopy. The images, provided as supporting material, confirmed the similar topography and structures' size scales. The elemental analysis of the prepared samples using EDS confirms that the porous nano-network is composed of carbon atoms. The reported weight percentages are carbon: $72.38 \mathrm{wt} \%, \mathrm{Al}: 27.22 \mathrm{wt} \%$ which is the substrate, and an insignificant rate of contamination of only $0.4 \mathrm{wt} \%$. The AFM typical images and elemental analysis diagram are provided in the Supported Figure S2.

The wetting analysis of the prepared smooth Al substrate directly coated with CS for various time periods is shown in Figure 3. Overall, all surfaces showed high water repellant properties with high CAs ranging from $147^{\circ}$ to $160^{\circ}$ and low SAs ranging from $21^{\circ}$ to $5^{\circ}$. However, the superhydrophobic property with CA of more than $150^{\circ}$ and SA of less than $10^{\circ}$ was only recorded for the surfaces with the short deposition time period of 3 and $5 \mathrm{~s}$. Interestingly, the smooth Al surface coated with CS for $5 \mathrm{~s}$ showed a higher CA of $160^{\circ}$ and lower SA of only $5^{\circ}$. This is due to the conformal coating and stability of the nano-network compared to the $3 \mathrm{~s}$ deposition sample. The trend of decrease in CAs and increase in SAs with an increase in the deposition time is caused by the decrease in the porosity of the surfaces as a result of increased nanoparticle sizes and their agglomeration. In terms of adhesion of the CS coating to the Al substrate, they all suffer from poor stickiness and are peeled off during the wetting analysis. However, the surfaces coated for a long period of time of 20 and $40 \mathrm{~s}$ showed relatively better adhesion but lower water repellant properties compared to the coatings formed for a short period of time.

To improve the overall robustness of the CS coating, its adhesion to the Al substrate, and its nano-network, CS was deposited on pre-roughened Al substrates. Accordingly, micro rough structures were introduced onto Al substrates by the simple technique of mechanical sanding using various sandpaper grit sizes. Figure $4 a-d$ show the SEM images of Al substrates sanded with grit sizes of 60,100,220, and 400, respectively. As a result, micro-grooves and bump-like microstructures of around 5-20 microns in width were formed. Their sizes decrease with an increase in the sandpaper grit size but the density also increases, which can also be noticed in the high resolution corresponding inset SEM images. Saifaldeen et al. [23] also utilized mechanical sanding using sandpapers with different grit sizes $(36,60,120,400$, and 1000) to impart micro rough structures to Al alloy with various dimensions. Figure $4 \mathrm{e}-\mathrm{h}$ shows the SEM images of various micro rough $\mathrm{Al}$ substrates coated with CS for the time duration of $5 \mathrm{~s}$. It can be noticed that the porosity of the double-layered rough surfaces decreased with the in-sandpaper grit sizes or decreased in the size of microstructures. This trend is due to the increase in density and size of nanostructured carbon nanoparticles with the decrease in the size of rough microstructures Al substrate. 


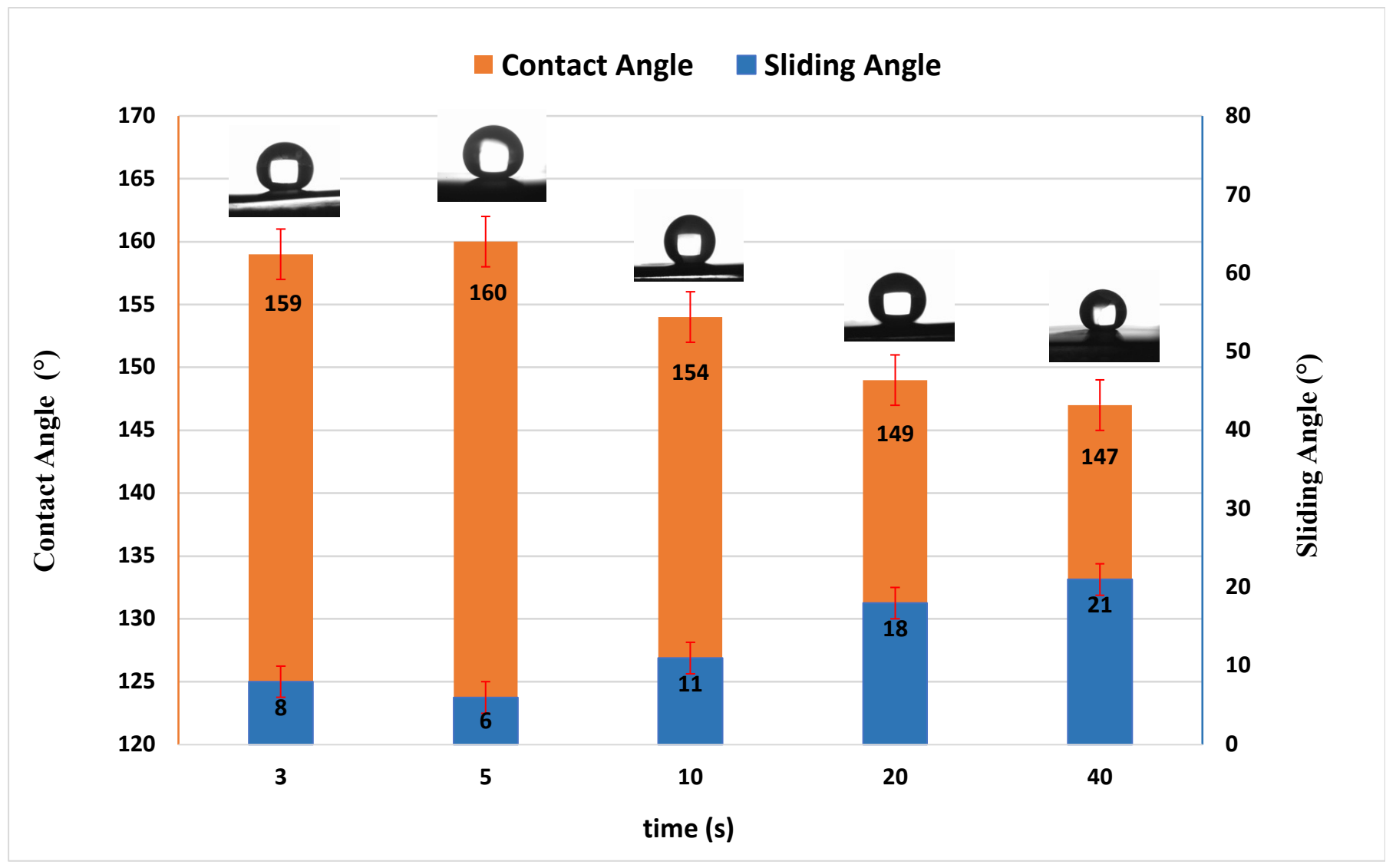

Figure 3. Water droplet contact angle (CA) and sliding angle (SA) values for surfaces with candle soot nano-network directly coated on smooth Al substrates for various time periods of 3, 5, 10, 20, and $40 \mathrm{~s}$.

Furthermore, the size of agglomerated CS nanoparticles formed on rough Al substrates is smaller compared to the ones formed on the smooth $\mathrm{Al}$ substrate. The average size of nanoparticles formed on rough Al substrate ranged between 30 to $50 \mathrm{~nm}$ for 60 and 400 sandpaper grit sizes, respectively. This indicates that the large surface area of rough Al substrate presents more nucleation sites for carbon atoms to agglomerate, resulting in smaller size agglomerated nanoparticles but with larger density. This is an indication of the formation of a more porous and stable CS coating. Previous studies have shown that the combination of micro-nano rough structures improved the porosity and robustness of the developed coating compared to a coating with either nano or micro rough structures $[5,9,14,21]$.

The wetting analyses of the micro-rough $\mathrm{Al}$ substrates developed by using various sandpaper grit sizes and then coated with CS for $5 \mathrm{~s}$ are presented in Figure 5. The CA and SA values indicate that the surfaces with a combination of microstructures coated with CS nano-network all showed superhydrophobic properties with CA of more than $150^{\circ}$ and SA of less than $10^{\circ}$. Meanwhile, the surface with the largest micro rough structures imparted by the sandpaper with the smallest grit size of 60 showed the highest $C A$ of $166^{\circ}$ and the lowest SA of only $2^{\circ}$ after being directly coated with CS. The presented data in Figure 5 also show that both CAs and SAs of water droplets slightly decreased with the increase in the sandpaper grit size which reflects the decrease in the size of microstructures. This indicates that imparted micro groove-like structures imparted on Al substrate by small sandpaper grit sizes are deep enough to better support the Cassie state of wetting; the water droplet floating over the air pockets trapped within both micro-nano structures. At some point, the measurement of CAs and SAs was challenging for the surfaces as the water droplet was barely touching the solid surface and quickly rolling off the surface. 


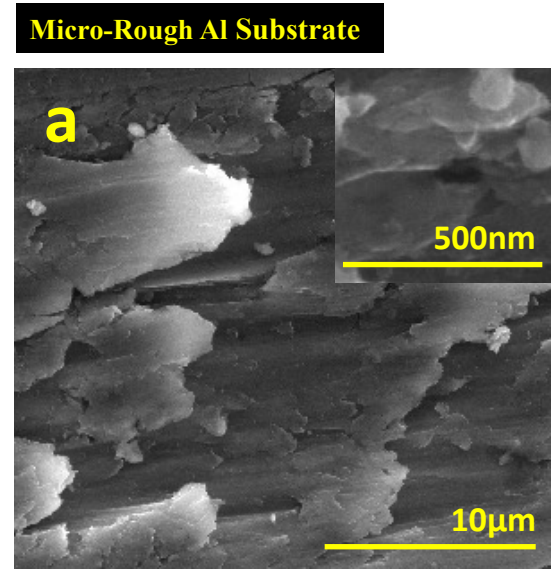

\section{Candle soot/ Micro-Rough Al Substrate}
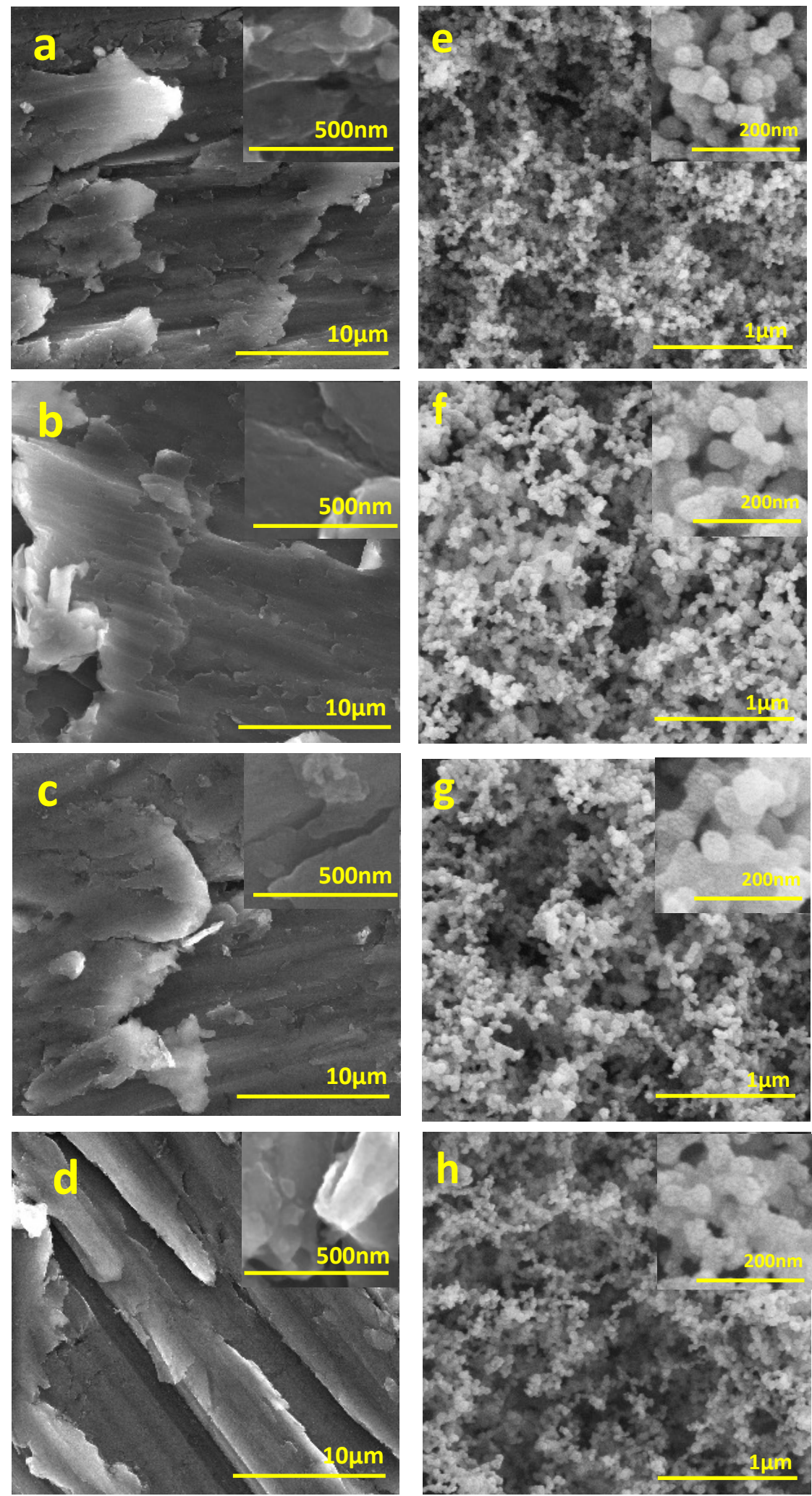

Figure 4. (a-d) SEM images of micro roughened $\mathrm{Al}$ substrates using various sandpaper grit sizes of $60,100,220$, and 400, respectively, and (e-h) Corresponding micro-rough Al substrates directly coated with nano-network CS for $5 \mathrm{~s}$ deposition time. 


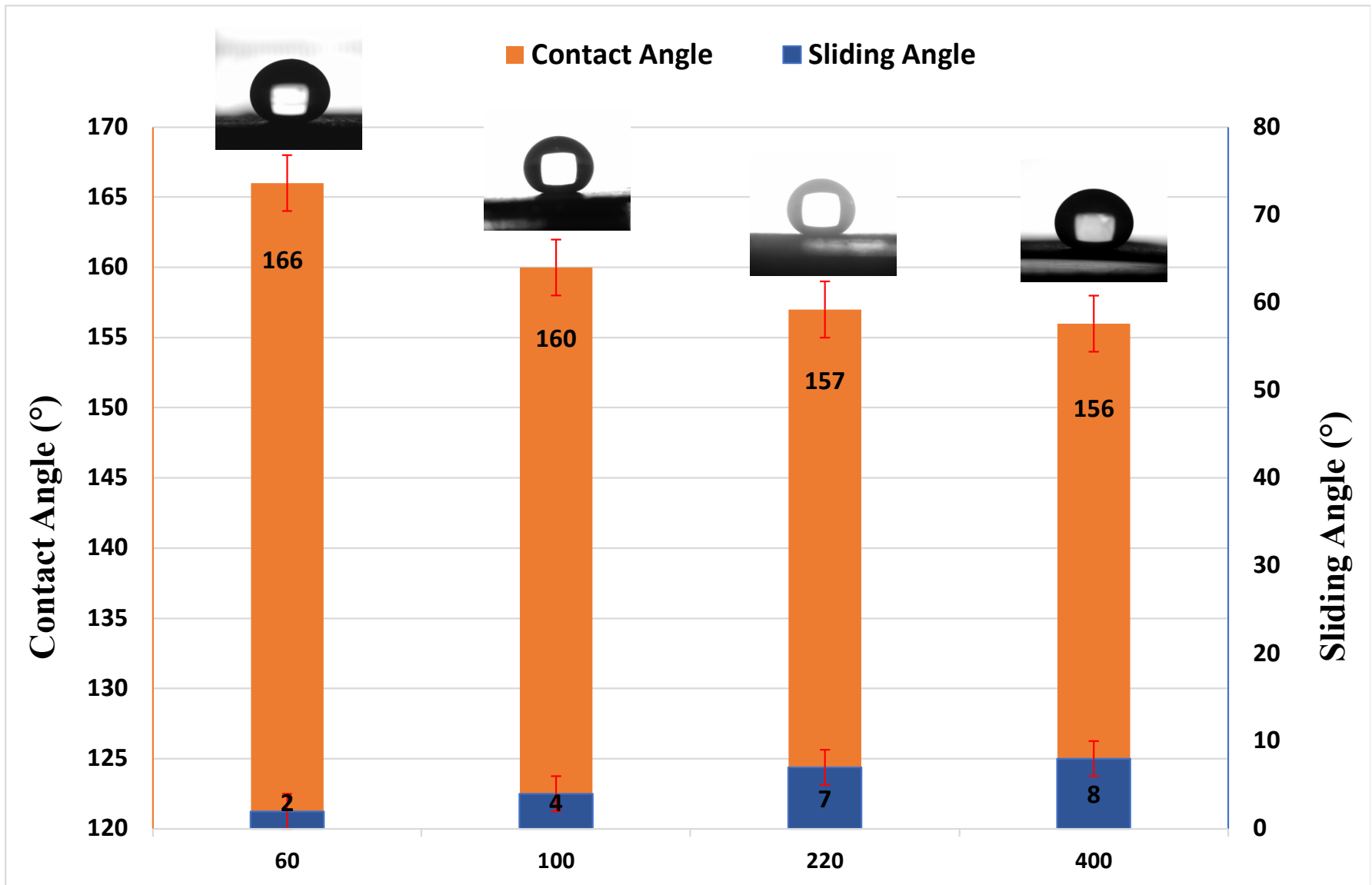

Sandpaper Grit Size

Figure 5. Water droplets contact angle (CA) and sliding angle (SA) values for nano-network candle soot surfaces directly coated on micro-rough Al substrates for $5 \mathrm{~s}$ deposition time versus sanded paper grit sizes used to impart micro-rough structures.

\section{Robustness Test}

In this part of the work, the robustness of the CS nano-network; its adhesion to the substrates, and its superhydrophobic sustainability were investigated. An amount of 2 microliter water as droplets has continuously impinged on the prepared surfaces from two different heights of 5 and $10 \mathrm{~cm}$. The reason behind using two different heights for water droplet impingement was to see the differential level of robustness of the prepared surfaces. Typical surfaces with optimal superhydrophobic properties, highest CA and lowest SA, from the two sets of nano and micro-nano coatings, were selected for the test. Figure 6a shows the CA values of CS coated on smooth Al substrate before and after performing the robustness test. The surfaces lost their superhydrophobic properties entirely with post-treatment droplet CA of less than $90^{\circ}$ from both impingement heights. The photographs of the samples before and after treatment, presented in Figure 6b, show that the CS coating was partially removed from the substrate for $5 \mathrm{~cm}$ impingement height while entirely removed for $10 \mathrm{~cm}$ impingement height. 
a

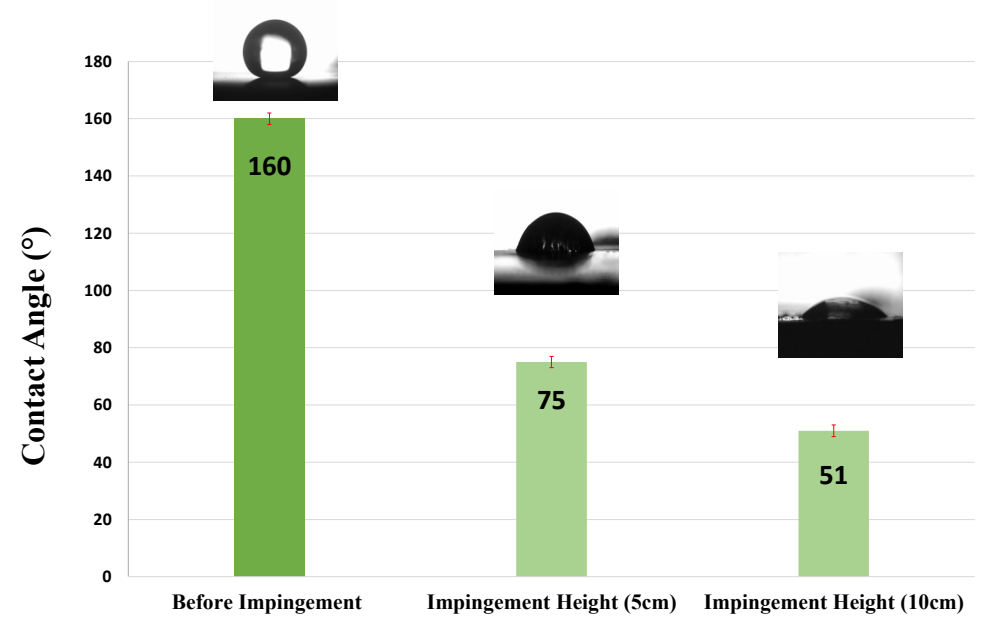

b

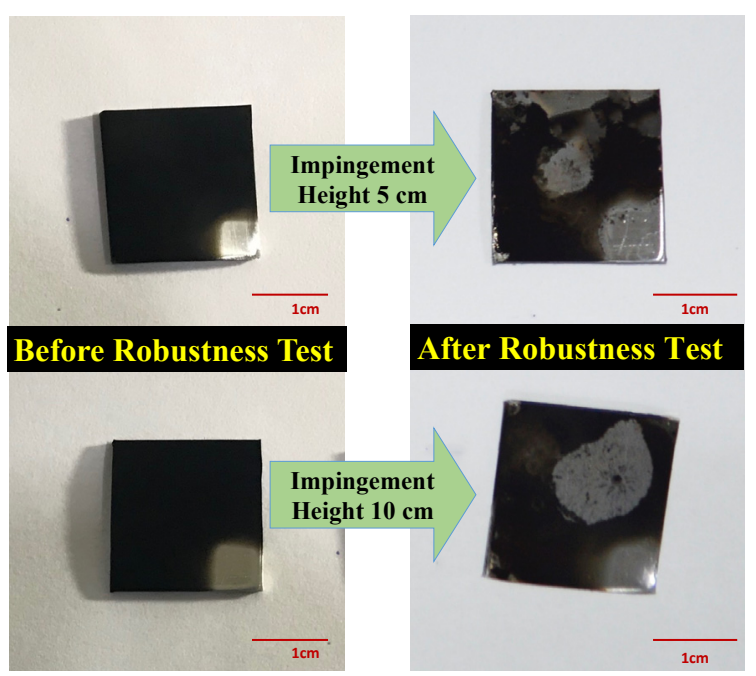

Figure 6. Wetting analysis of the prepared surfaces of candle soot coated on smooth Al substrate with the highest superhydrophobic properties before and after impingement of water droplets from two different heights of 5 and $10 \mathrm{~cm}$; (a) contact angle (CA) measurements (b) Digital photographs of the surfaces.

In their study, Zhang et al. [9] also reported that the superhydrophobic surfaces prepared by a direct coating of CS on smooth $\mathrm{Al}$ substrate suffered from low adhesion. The robustness of the surfaces was improved by pre-coating of the Al substrate with PDMS. In another study by Qahtan et al. [20] the CS was coated on glass substrate using both direct and spraying techniques. It was shown that the prepared coatings were superhydrophobic with a high contact angle of $163^{\circ}$ and a low sliding angle of less than $10^{\circ}$. They also showed that surfaces prepared by direct coating suffer from low adhesion and the robustness was improved by spray coating of the CS.

In the case of double-layer roughness, CS coated on micro rough Al substrate, the surfaces relatively maintained their superhydrophobic properties after being subjected to the robustness test. Figure 7a presents the $\mathrm{CA}$ values of the surfaces for both impingement heights of 5 and $10 \mathrm{~cm}$. It shows that the surface maintained its superhydrophobic properties with a water $\mathrm{CA}$ of $150^{\circ}$ for $5 \mathrm{~cm}$ impingement height, as shown in a video provided in the Supplementary Materials as Videotape S1. The surfaces lost their superhydrophobic property but still maintained their high hydrophobic property with water $\mathrm{CA}$ of $135^{\circ}$ when the impingement height was increased to $10 \mathrm{~cm}$. Digital photos of the surfaces, Figure $7 \mathrm{~b}$, confirm the fact that the CS coating is still intact for $5 \mathrm{~cm}$ impingement height and partially removed for $10 \mathrm{~cm}$ impingement height. In conclusion, the micro roughened $\mathrm{Al}$ substrate enhanced the adhesion of the CS nano-network to the substrate, in addition to its enhanced superhydrophobicity [26,27]. We believe that the increased surface area of high surface energy $\mathrm{Al}$ substrate promoted more contact area with the low surface energy CS which in turn enhances the adhesion and its internal compactness. Manipulation of the CS coating's thickness could also present more insights into the improvement of its robustness and consequently a wider range of applications. 
a

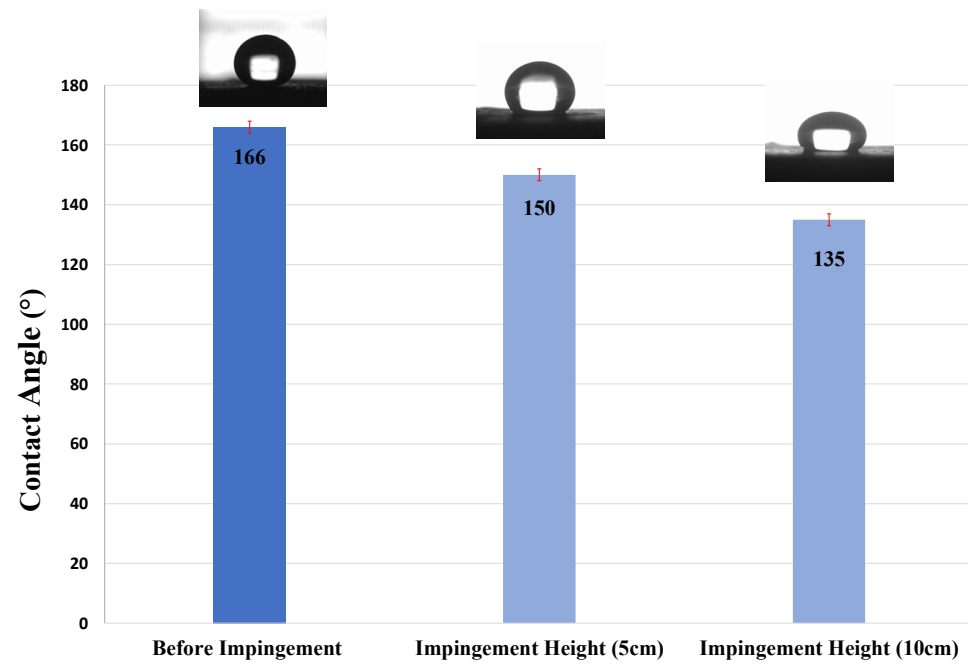

b

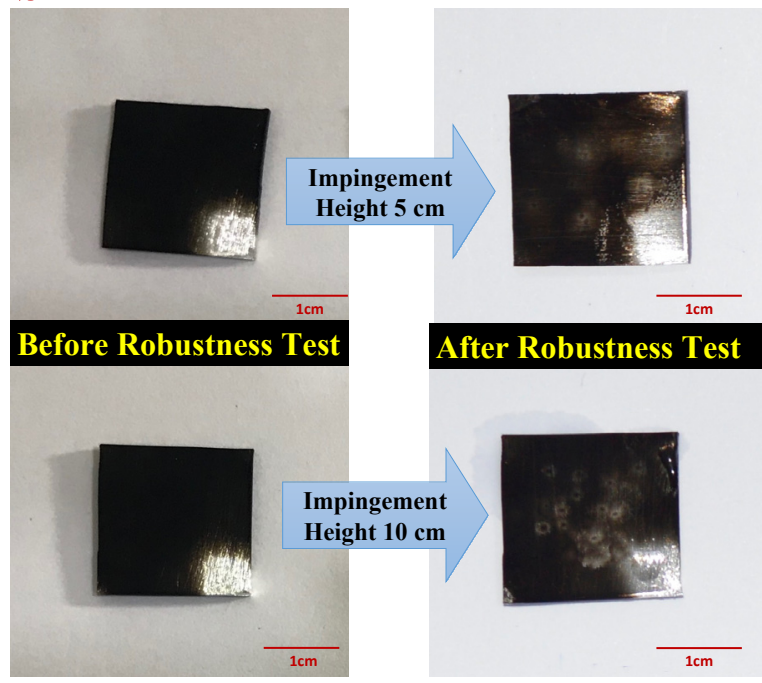

Figure 7. Wetting analysis of the candle soot coated on micro-rough Al substrate with the highest superhydrophobic properties before and after impingement of water droplets from two different heights of 5 and $10 \mathrm{~cm}$; (a) contact angle (CA) measurements (b) Digital photographs of the surfaces.

\section{Conclusions}

Robust superhydrophobic coatings on metallic surfaces using simple and environmentally friendly techniques were developed. The waste material of candle soot and a simple mechanical sanding technique was used to develop these surfaces. Candle soot material directly coated onto smooth $\mathrm{Al}$ substrate showed superhydrophobic properties but with a lack of robustness. The candle soot material coated on roughened Al substrate significantly showed improved superhydrophobic property as well as the robustness of the coating. The hierarchical roughness, micro rough Al structures coated with nano network of candle soot material, significantly contributed to the enhancement of the coating's water repellant and mechanical robustness properties. The developed coatings in this study could see applications in areas such as self-cleaning and anti-icing.

Supplementary Materials: The following supporting information can be downloaded at: https:/ / www.mdpi.com/article/10.3390/coatings12020202/s1, Figure S1: The homemade contact angle measurement unit used for performing wetting analysis; Figure S2: The AFM for (a) CS deposited on smooth Al Substrate, (b) CS deposited on micro-rough Al Substrate, and (c) shows the composition of the coated samples; Figure S3: The thickness of candle soot coating deposited on smooth $\mathrm{Al}$ substrate versus their deposition time. Videotape S1: The video showing the robustness test for the prepared superhydrophobic surfaces of candle soot coated on rough Al substrate by water droplet impingement from a height of $5 \mathrm{~cm}$.

Author Contributions: Formal analysis, H.A.H.; Investigation, H.A.H.; Methodology, H.A.H.; Supervision, S.I.W. and K.R.K.; Writing-original draft, H.A.H.; Writing-review \& editing, S.I.W. and K.R.K. All authors have read and agreed to the published version of the manuscript.

Funding: This research received no external funding.

Institutional Review Board Statement: Not applicable.

Informed Consent Statement: Not applicable.

Data Availability Statement: Data is contained within the article or Supplementary Materials.

Conflicts of Interest: The authors declare no conflict of interest. 


\section{References}

1. Milles, S.; Soldera, M.; Kuntze, T.; Lasagni, A.F. Characterization of self-cleaning properties on superhydrophobic aluminum surfaces fabricated by direct laser writing and direct laser interference patterning. Appl. Surf. Sci. 2020, 525, 146518. [CrossRef]

2. Xu, S.; Wang, Q.; Wang, N. Eco-friendly fabrication of superhydrophobic surface with anti-corrosion by transferring dendrite-like structures to aluminum substrate. Colloids Surf. A Physicochem. Eng. Asp. 2020, 595, 124719. [CrossRef]

3. Nguyen, V.-H.; Nguyen, B.D.; Pham, H.T.; Lam, S.S.; Vo, D.-V.N.; Shokouhimehr, M.; Vu, T.H.H.; Nguyen, T.-B.; Kim, S.Y.; Van Le, Q. Anti-icing performance on aluminum surfaces and proposed model for freezing time calculation. Sci. Rep. 2021, 11, 1-9. [CrossRef] [PubMed]

4. Barthwal, S.; Lim, S.-H. A durable, fluorine-free, and repairable superhydrophobic aluminum surface with hierarchical micro/nanostructures and its application for continuous oil-water separation. J. Membr. Sci. 2021, 618, 118716. [CrossRef]

5. Xu, C.; Shi, Z.; Wu, Z.; Zhang, F.; Gu, L.; Wang, Y.; Zhou, X.; Peng, C. Fabrication of superhydrophobic soot-like surface. In Proceedings of the 2016 IEEE International Conference on Manipulation, Manufacturing and Measurement on the Nanoscale (3M-NANO), Chongqing, China, 18-22 July 2016; pp. 400-403.

6. Deng, X.; Mammen, L.; Butt, H.-J.; Vollmer, D. Candle soot as a template for a transparent robust superamphiphobic coating. Science 2012, 335, 67-70. [CrossRef] [PubMed]

7. Esmeryan, K.; Radeva, E.; Avramov, I. Durable superhydrophobic carbon soot coatings for sensor applications. J. Phys. D Appl. Phys. 2015, 49, 025309. [CrossRef]

8. Yang, L.; Fu, H.; Yang, C.; Tian, W.; Wu, P.; Jiang, W. Carbon soot with arbitrary wettability deposited on solid surface by ethanol flame method. Colloids Surf. A Physicochem. Eng. Asp. 2019, 578, 123576. [CrossRef]

9. Zhang, B.; Duan, J.; Huang, Y.; Hou, B. Double layered superhydrophobic PDMS-Candle soot coating with durable corrosion resistance and thermal-mechanical robustness. J. Mater. Sci. Technol. 2021, 71, 1-11. [CrossRef]

10. Zhang, X.; Zhao, J.; Mo, J.; Sun, R.; Li, Z.; Guo, Z. Fabrication of superhydrophobic aluminum surface by droplet etching and chemical modification. Colloids Surf. A Physicochem. Eng. Asp. 2019, 567, 205-212. [CrossRef]

11. Dai, W.; Kim, S.J.; Seong, W.-K.; Kim, S.H.; Lee, K.-R.; Kim, H.-Y.; Moon, M.-W. Porous carbon nanoparticle networks with tunable absorbability. Sci. Rep. 2013, 3, 1-9. [CrossRef]

12. Sutar, R.S.; Latthe, S.S.; Nagappan, S.; Ha, C.S.; Sadasivuni, K.K.; Liu, S.; Xing, R.; Bhosale, A.K. Fabrication of robust self-cleaning superhydrophobic coating by deposition of polymer layer on candle soot surface. J. Appl. Polym. Sci. 2021, 138, 49943. [CrossRef]

13. Rico, V.J.; López-Santos, C.; Villagrá, M.N.; Espinós, J.P.; de la Fuente, G.F.; Angurel, L.A.; Borrás, A.; González-Elipe, A.N.R. Hydrophobicity, freezing delay, and morphology of laser-treated aluminum surfaces. Langmuir 2019, 35, 6483-6491. [CrossRef]

14. Guo, Y.; Zhang, X.; Wang, X.; Xu, Q.; Geng, T. Wetting and tribological properties of superhydrophobic aluminum surfaces with different water adhesion. J. Mater. Sci. 2020, 55, 11658-11668. [CrossRef]

15. Lu, Y.; Guan, Y.; Li, Y.; Yang, L.; Wang, M.; Wang, Y. Nanosecond laser fabrication of superhydrophobic surface on 316L stainless steel and corrosion protection application. Colloids Surf. A Physicochem. Eng. Asp. 2020, 604, 125259. [CrossRef]

16. Khedir, K.R.; Kannarpady, G.K.; Ishihara, H.; Woo, J.; Ryerson, C.; Biris, A.S. Design and fabrication of teflon-coated tungsten nanorods for tunable hydrophobicity. Langmuir 2011, 27, 4661-4668. [CrossRef]

17. Vilaró, I.; Yagüe, J.L.; Borrós, S. Superhydrophobic copper surfaces with anticorrosion properties fabricated by solventless CVD methods. ACS Appl. Mater. Interfaces 2017, 9, 1057-1065. [CrossRef]

18. Lei, T.; Xiong, J.; Huang, J.; Zheng, T.; Cai, X. Facile transformation of soot nanoparticles into nanoporous fibers via single-step electrospinning. AIP Adv. 2017, 7, 085212. [CrossRef]

19. Tang, Y.; Zhang, Q.; Zhan, X.; Chen, F. Superhydrophobic and anti-icing properties at overcooled temperature of a fluorinated hybrid surface prepared via a sol-gel process. Soft Matter 2015, 11, 4540-4550. [CrossRef]

20. Qahtan, T.F.; Gondal, M.A.; Alade, I.O.; Dastageer, M.A. Fabrication of water jet resistant and thermally stable superhydrophobic surfaces by spray coating of candle soot dispersion. Sci. Rep. 2017, 7, 1-7. [CrossRef]

21. Gong, A.; Zheng, Y.; Yang, Z.; Guo, X.; Gao, Y.; Li, X. Spray fabrication of superhydrophobic coating on aluminum alloy for corrosion mitigation. Mater. Today Commun. 2021, 26, 101828. [CrossRef]

22. Zhao, L.; Zhao, K.; Yan, W.-G.; Liu, Z. Preparation of assembled carbon soot films and hydrophobic properties. Materials 2018, 11, 2318. [CrossRef] [PubMed]

23. Saifaldeen, Z.S.; Khedir, K.R.; Cansizoglu, M.F.; Demirkan, T.; Karabacak, T. Superamphiphobic aluminum alloy surfaces with micro and nanoscale hierarchical roughness produced by a simple and environmentally friendly technique. J. Mater. Sci. 2014, 49, 1839-1853. [CrossRef]

24. Khedir, K.R.; Saifaldeen, Z.S.; Demirkan, T.M.; Al-Hilo, A.A.; Brozak, M.P.; Karabacak, T. Robust superamphiphobic nanoscale copper sheet surfaces produced by a simple and environmentally friendly technique. Adv. Eng. Mater. 2015, 17, 982-989. [CrossRef]

25. Rico, V.; Mora, J.; García, P.; Agüero, A.; Borrás, A.; González-Elipe, A.R.; López-Santos, C. Robust anti-icing superhydrophobic aluminum alloy surfaces by grafting fluorocarbon molecular chains. Appl. Mater. Today 2020, 21, 100815. [CrossRef]

26. Barthwal, S.; Lim, S.-H. Rapid fabrication of a dual-scale micro-nanostructured superhydrophobic aluminum surface with delayed condensation and ice formation properties. Soft Matter 2019, 15, 7945-7955. [CrossRef]

27. Milles, S.; Dahms, J.; Soldera, M.; Lasagni, A.F. Stable Superhydrophobic Aluminum Surfaces Based on Laser-Fabricated Hierarchical Textures. Materials 2021, 14, 184. [CrossRef] 
28. Esmeryan, K.D.; Castano, C.E.; Fedchenko, Y.I.; Mohammadi, R.; Miloushev, I.K.; Temelkov, K.A. Adjustable optical transmittance of superhydrophobic carbon soot coatings by in-situ single-step control of their physicochemical profile. Colloids Surf. A Physicochem. Eng. Asp. 2019, 567, 325-333. [CrossRef]

29. Seo, K.; Kim, M. Candle-based process for creating a stable superhydrophobic surface. Carbon 2014, 68, 583-596. [CrossRef]

30. Wu, S.; Du, Y.; Alsaid, Y.; Wu, D.; Hua, M.; Yan, Y.; Yao, B.; Ma, Y.; Zhu, X.; He, X. Superhydrophobic photothermal icephobic surfaces based on candle soot. Proc. Natl. Acad. Sci. USA 2020, 117, 11240-11246. [CrossRef]

31. Wei, Q.; Zhu, Y.; Liu, S.; Gao, Y.; Li, X.; Shi, M.; Zhang, X.; Zhang, M. Candle Soot Coating for Latent Fingermark Enhancement on Various Surfaces. Sensors 2017, 17, 1612. [CrossRef] 